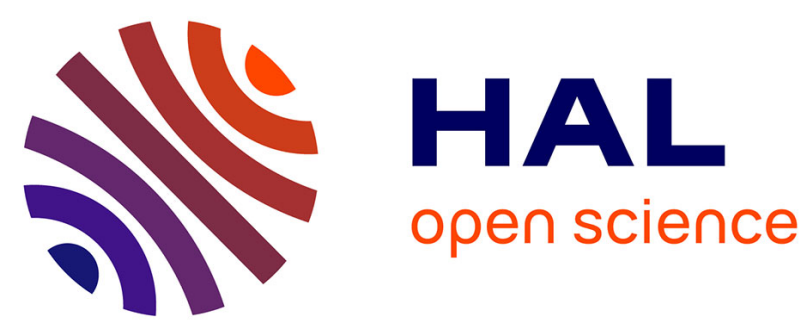

\title{
Slope effects on the fluid dynamics of a fire spreading across a fuel bed: PIV measurements and $\mathrm{OH}^{*}$ chemiluminescence imaging
}

Frédéric Morandini, Xavier Silvani, David Honoré, Guillaume Boutin, Arnaud

Susset, Romain Vernet

\section{To cite this version:}

Frédéric Morandini, Xavier Silvani, David Honoré, Guillaume Boutin, Arnaud Susset, et al.. Slope effects on the fluid dynamics of a fire spreading across a fuel bed: PIV measurements and $\mathrm{OH}^{*}$ chemiluminescence imaging. Experiments in Fluids, 2014, 55, pp.1788. 10.1007/s00348-014-1788-3 . hal-01064508

\section{HAL Id: hal-01064508 \\ https://hal.science/hal-01064508}

Submitted on 16 Sep 2014

HAL is a multi-disciplinary open access archive for the deposit and dissemination of scientific research documents, whether they are published or not. The documents may come from teaching and research institutions in France or abroad, or from public or private research centers.
L'archive ouverte pluridisciplinaire HAL, est destinée au dépôt et à la diffusion de documents scientifiques de niveau recherche, publiés ou non, émanant des établissements d'enseignement et de recherche français ou étrangers, des laboratoires publics ou privés. 


\title{
Slope effects on the fluid dynamics of a fire spreading across a fuel bed: PIV measurements and $\mathrm{OH}^{*}$ chemiluminescenceimaging
}

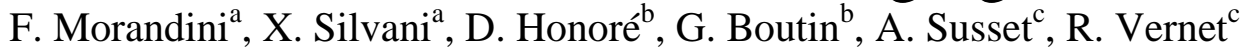

${ }^{\text {a }}$ SPE UMR 6134, CNRS, Université de Corse, BP 52, 20250 Corte, France

${ }^{\mathrm{b}}$ CORIA UMR 6614, CNRS, INSA de Rouen, Université de Rouen, Normandie Université, 76821 Saint Etienne du Rouvray, France

${ }^{c}$ R\&DVision, 64, rue Bourdignon, 94100 St Maur des Fossés, France

\section{Corresponding author:}

F. Morandini

E-mail address: frederic.morandini@univ-corse.fr

Shortened title:Slope effects on fire fluid dynamics

\begin{abstract}
Slope is among the most influencing factor affecting the spread of wildfires. A contribution to the understanding of the fluid dynamics of a fire spreading in these terrain conditions is provided in thepresent paper. Coupled optical diagnostics are used to study the slope effects on the flow induced by a fire at laboratory scale. Optical diagnostics consist of Particle Image Velocimetry, for investigating the 2D (vertical) velocity field of the reacting flow and chemiluminescence imaging, for visualizing the region of spontaneous emission of $\mathrm{OH}$ radical occurring during gaseous combustion processes. The coupling of these two techniques allowslocating accurately the contour of the reaction zone within the computed velocity field. The series of experiments are performed across a bed of vegetative fuel,under both no-slope and $30^{\circ}$ up-slope conditions. The increase of the rate of fire spread with increasing slope is attributed to a significant change in fluid dynamics surrounding the flame. For horizontal fire spread, flame fronts exhibit quasi-vertical plume resulting in the buoyancy forces generated by the fire. These buoyancy effects induce an influx of ambient fresh air which is entrained laterally into the fire, equitably from both sides. For upward flame spread, the induced flow is strongly influenced by air entrainment on the burnt side of the fireand fire plume is tilted towards unburned vegetation.A particular attention is paid to the induced air flow ahead of the spreading flame. With increasing the slope angle beyond a threshold, highly dangerous conditions arise because this configurationinduces wind blows away from the fire rather than towards it, suggesting the presence of convective heat transfers ahead of the fire front.
\end{abstract}

Keyword:Fluid dynamics; Fire spread; Slope effects, Particle Image Velocimetry; Chemiluminescence 


\section{Introduction}

Slope is one of the most influencing factors affecting the spread of wildfires due to the interactions between the flow induced by the fire and the inclined terrain. Viegas(2006) pointed out thecontinuous increase of the rate of spread of the head of a fire front travelling up a hill, even withoutany significant change of environmental parameter (slope, wind, vegetation, etc.) due toconvective effects induced by the fire itself. A large number of fatal accidents during fire fightinghave been reportedunder steep slope conditions in the open (eruptive behavior)or even in a confined space (trench effect). The mechanisms of fire spreading across a slope thus deserve particular attention. Primary laboratory studies on the slope effects focused on the fire dynamics and geometrical flame properties (Dupuy 1994; Mendes-Lopes et al. 2003; Dupuy and Maréchal2011)but the local air flow induced by the fire was not directly examined in these experiments. Dupuy and Maréchal(2011) and Silvaniet al.(2012)further investigated the heat transfer processes using heat flux gauges. The authors have shown that radiant heat transfer from flames to the unburned fuel bed dominates the slope effect in vegetative beds of fuel when slope angle increases from 0 to $20^{\circ}$, but that convection becomes dominant when slope angle increases to 30.But the reason why convection becomes dominant remains tobeinvestigated since the properties of the flow were not known. Some answers can be found through exploring the fluid dynamics.

Dupuy et al.(2011)and Silvaniet al.(2012)also examined the flow thanks to the visible emission of flames and the presence of smoke emitted from the burnt area using top-rear camera.Recordings pointed out the presence of vortices moving along the two fire flanks towards the fire head but the flow ahead of the flame front was not observable.Doldand Zinoviev(2009)underlined the importance of studyingthe air flow immediately ahead of a fire when it is burning up aslopeand more particularly if this flow is separated from the ground surface or attached to it.Observations were made during upslope fire spread experiments at laboratory scale using a simple and ingenious method based on the displacement of soap bubbles. The bubbles were seen to be carried down the slope towards the flames for $25^{\circ}$ incline but to be blown up the slope, away from the fire, in the cases of $30^{\circ}$ inclines and beyond.The author also reported the change in the flow behavior from observations of light piece of cloth tied to the vegetation during a field experiment. The analogy has often been invoked between the wind and slope suggesting that both factors causedsimilar effects, bringing flames closer to the unburned fuel, increasing heat transfers and modifying the air flow. Anderson et al. (2010) discussed a method used to measure convective heating in a large set of laboratory fires under both still air and windblown conditions. This study describes the gas and fuel temperatures and the local gas speed at fuel bed level using thermocouples and kiel-static probes, as functions of the distance from the flame front. The results showed that, as the fire front approaches, the blocking effect of the flame causes the air velocity ahead of the flame front to decrease to a minimum value, which, in zero-wind fires, is negative (reversal of flow towards the fire). The authors indicated furthermore that as the flame front approaches, the air temperature near the fuel particle rises slowly but remains below the fuel temperature resulting in convective cooling. The authors argued that forzero-wind fires, the process of convective heating must be primarilyby natural convection and turbulent diffusion. However, no accurate measurements of the flame front location associated to the velocity field were available to confirm these findings.

Beside these experimental observations, modeling approachesof fire spread based on CFDconstitute a first alternative to the understanding of the fluid dynamics of a fire spreadingupslope. Indeed, numerical simulations can predict the main flow characteristics,such as the field of velocity vectors. The influence of the topography on the ambient wind field at the base of the fire was shown by Linn et al. (2007). Dupuy and 
Morvan(2005)examined slope effects on fire behavior and the model predicted the main expected responses of wildfires to slopes. The numerical study highlighted the travelling of vortices ahead of the fire front that may cause long-rangeignitions, increasing the fire danger in the case of up-slope fires. Zhou et al.(2007) presented a combined study of laboratory-scale fire spread experiments and a three-dimensional large eddy simulation to analyze the effect of terrain slope on marginal burning behavior in live chaparral shrub fuel beds. The authors found that upslope fire spread depends not only on the increased radiant heat transfer but also on the aerodynamics effect created by the interaction of the flame with the slope. The predictions also show that under certain conditions, the convective heat transfer induced by this interaction becomes the dominant mechanism in determining fire spread success. Unfortunately, the detailed flow field in the experimental fires was unavailable because of the limited measurement capability.

The investigation of the airflow surrounding the flame can therefore improve significantly the knowledge on how fire spreads and on the involved heat transfer processes. The measurement of the fluid flow can be realized by means of optical methods. These non intrusive measurement techniques have the advantage of not modifying the flow to be measured. Clark et al.(1999) aimed to produce wildfire data that describe the very small timescale and spatial scale involved in the convective processes in order to help to determine fire spread. To this end, the authors applied a gradient-based image flow analysis scheme to a sequence of high-frequency, high-resolution infrared images during an intense crown fire to derive wind fields and sensible heat flux. The image flow analysis indicated a number of physical mechanisms that contribute to the rate of spread, such as the enhanced tilting of horizontal vortices leading to counter rotating convective towers such that air between the towers blew in the direction of fire spread at canopy height and below.Lazanoet al.(2010) employed Particle Image Velocimetry (PIV)to investigate the fluid dynamic structures within thethree regions of a flame (continuous, intermittent, and thermal plume) spreading across a bed of excelsior for horizontal fire spread in still air. From the velocity field measurements, the authorsargued that convective heating assists preheating at a very short distance downwind of the flame front. It should be noted that the flame contour itself could not be visualized with the velocity vectors, which makes difficult the localization of the area ahead of the flame front. The position of center of the fire propagationwas nevertheless estimatedby plotting the positions of maximum vertical and minimum horizontal velocities along the fuel bed.

The properties of the turbulent flow being scale dependant, fires tests should preferably be conducted with dimensionsclose to the ones of the studied phenomenon, in order to capture the wider range of scale of the reacting flow. In a previous study, Morandini et al.(2012)showed the feasibility of large-scalePIV measurements with fire spreading across under wind-blown conditions in the open.The bed of excelsior $\left(50 \mathrm{~m}^{2}\right)$ produced turbulent flames representative of low intensity wildfires.In our ongoing effort to improve the understanding of the complex flow mechanisms governing the behavior of fires, a series of PIV experiments across sloping beds are also plannedin a large scale facility (Dupuy and Maréchal2011; Dupuyet al. 2011;Silvaniet al.2012).The currentstudy of the effect of slope on fire spreading at laboratory-scale $\left(1 \mathrm{~m}^{2}\right)$ will be also used as guidelines to define a setup of the whole fluid visualization method which would be implemented in upslope fire tests at large scale. Optical diagnostics consist of PIV, for investigating the 2D (vertical) velocity field of the reacting flow and chemiluminescence imaging, for visualizing the region of spontaneous emission of $\mathrm{OH}^{*}$ radical occurring during gaseous combustion processes. In spite of their limited scale, these fire tests contribute to the understanding of the interaction of the slope and the fire induced aerodynamics. 


\section{Experimental protocol}

The complete schematic of the experimental setup is shown in Fig. 1. The laboratory-scale bench has an inclinable plate made of a refractory material (Siporex) that can be set at angles of 0 and $30^{\circ}$. These configurations are retained since previous studies (Dupuy and Maréchal2011; Dupuyet al. 2011;Silvaniet al.2012) exhibited a change in fire spread regime for slope angles greater than $20^{\circ}$.The combustion table is located under a smoke exhaust system located high enough $(3 \mathrm{~m})$. PIV measurements without fire were performed to ensure that the smoke exhaust system do not disturb the flow in the measuring region. The fuel bed consisted of a $0.85 \mathrm{~m}$-long and $0.45 \mathrm{~m}$-wide bed of excelsior. Fuel moisture content is close to $8 \%$.Fire is ignited along a line at one of the edges of the plate.In order to perform repeatable fire runs, a constant fuel load $\left(0.4 \mathrm{~kg} \cdot \mathrm{m}^{-2}\right)$, fuel bed thickness $(5 \mathrm{~cm})$, fuel homogeneity, and bed bulk density are maintained during the experiments. Given the density of the fuel particles $\left(830 \mathrm{~kg} / \mathrm{m}^{3}\right)$, the actual fuel packing ratio was close to $0.96 \%$.For horizontal and upslope configurations, 5 and 4 temporal series of PIV and $\mathrm{OH}^{*}$ chemiluminescence imaging are recorded during the whole fire propagation (Table 1), respectively. Each experiment represents about 500 successive couples of $\mathrm{OH}^{*}$ images and velocity fields for no-slope and about 200 for $30^{\circ}$ slope experiments.

\subsection{Particle image velocimetry}

The velocity field in the vicinity and inside the spreading flameis measured using a PIV system which main elements are a CCD camera synchronized with a double pulsed laser. The flow is seeded with particles and illuminated by a laser vertical sheet generated using a set of optical lenses.

The illumination source used is a double cavity Nd:YAG laser delivering couples of pulses $(2 \times 200 \mathrm{~mJ} /$ pulse, $7 \mathrm{~ns} /$ pulse $)$ at a wavelength of $532 \mathrm{~nm}$ and a frequency of $10 \mathrm{~Hz}$. The laser beam is spread into a vertical sheet using an optical device composed of spherical convergent and divergent cylindrical lenses. The resulting laser sheet in the measurement area is $1 \mathrm{~m}$ high, $5 \mathrm{~mm}$ thick and focused at the centre of the fuel bed (Fig. 1). The time between the two laser pulses are $1.5 \mathrm{~ms}$ and $1.2 \mathrm{~ms}$ for no-slope and upslope conditions, respectively.

A PIV camera (Hamamatsu C9300-024, 2048×2048 pixels resolution, 12-bit dynamic range), located perpendicularly to the laser sheet, records the light scattered by illuminated seed particles in the vertical plane. The PIV measurement area isabout $0.71 \mathrm{~m} \times 0.71 \mathrm{~m}$. The camera is equipped of a $50 \mathrm{~mm}$ lens with a passband filter $532 \mathrm{~nm} \pm 1.5 \mathrm{~nm}$ centered on laser wavelength. The camera is synchronized with the laser double pulses using a multi-pulses generator from R\&D Vision. The measurement of the velocity field in presence of flame is difficult since standard PIV cameras cannot allow obtaining two consecutive images with the same short exposure times. This is due to the storage time of the first frame, which is not fast enough for the camera to be ready for a second exposure with the same characteristics. As a result, the second frame has usually an exposure time greater than the first one, which is a real issue in presence of a highly luminescentflame (over-exposition, blurring). For this purpose, a ferro-electric liquid crystal shutter allowing a short aperture time $(<100 \mu \mathrm{s})$ is also used to guaranty the same exposure time for the pairs of PIV images, and then avoid over exposure of the second image that would be due to the highly luminescent flame (Honoréet al. 2001).

A standard digital video camera (Guppy F080C-IRF, 1032×778 pixels resolution) with a $16 \mathrm{~mm}$ wide-anglelensisalso used to record the visible emission of the fire spread across the whole bed of fuel (Fig. 1). The cameras arelocated at about $2.3 \mathrm{~m}$ from the combustion table and the monitored area is perpendicular to the bench surface. For no-slope fire experiments the cameras are set horizontally and they are rotated around the same axis for upslope conditions. 
Measurements of velocity on the fire and its surrounding during its propagation require the seeding of ambient air with refractory particles adapted to PIV in combustion conditions. The seeding of the flow ismade using a laboratory-made cyclonic solid particles seeding device. The tracer particles are injected, far away, as a fine mist perpendicularly to the laser sheet (Fig. 1). For fire applications, the seeding material is zirconiumoxide $\left(\mathrm{ZrO}_{2}\right)$, with $5 \mu \mathrm{m}$ diameter because,thanks to their high fusion temperature $(2700 \mathrm{~K})$, these particles are not consumed into the flame. When PIV measurements are performed in a confined environment, the seeding of the flow is easier than in a large room with a smoke exhaust system on the roof. Preliminary tests without fire confirmed that neither the seeding process nor the smoke exhaust system introduce disruptive inertial forces.

The accuracy of the PIV measurements depends on several parameters: particles size and seeding density, displacement gradients in the measurement plan, 3D effects, the digital resolution of the images but also image processing technique. In the present study, the velocity fields are computed using DirectPIV 3.0 analysis software from R\&D Vision. The algorithm is based on a two-evaluation passes with a resizing method of the interrogation window (Sussetet al. 2006). The interrogation window size is $50 \times 50$ pixels with $60 \%$ overlap in both directions. The instantaneous velocity fields are then post-processed with different filters. A global filter that excludes velocities larger than a certain threshold is first applied. For no-slope fires, horizontal and vertical velocity components are filtered outsidethe ranges $[-2,2]$ and $[-2,4] \mathrm{m} / \mathrm{s}$, respectively. For up-slope fires, the filter rangesare $[-2,2]$ and $[-2,6]$ $\mathrm{m} / \mathrm{s}$, respectively. A local filter is applied to remove vectors that are significantly different from their neighbors. A ten steps iterative filtering with a maximum level of $75 \%$ is applied to remove spurious vectors in $7 \times 7$ area. A Gaussian interpolationis finally performed on spurious vectors.

\subsection{OH radical chemiluminescence imaging}

Chemiluminescence imaging is a convenient technique for characterizing structures and intensity of flames. The choice of imaging $\mathrm{OH}^{*}$ chemiluminescence in UV range allows to filter out any incandescent radiation from soot or solid fuel and any thermal radiation form hot parts and then to obtain instantaneous images of gaseous reaction zones (Honoré 2007). Simultaneous measurements by PIV and $\mathrm{OH}^{*}$ chemiluminescence imagingallow us to measure the flame properties but also to locate the region where combustion reactions occur or not within the velocity field.

In the present work, the technique consists of associating an intensified CCD camera (Roper Princeton Instruments IMAX2, 512×512 pixels resolution, 16-bit dynamic range) with a UV Goyo $25 \mathrm{~mm} \mathrm{f} / 2.8$ lens. The viewing area captured by the ICCD camerais about $0.8 \mathrm{~m} \times 0.8 \mathrm{~m}$. An interferential filter $308 \pm 10 \mathrm{~nm}$ (with a $50 \%$ transmissivityratio) is attached between the lens and CCD array. This allows filtering out the heat radiation from the soot and the combustion table materials at high temperature. The intensification gain iskept constant for all experiments.The intensification gate, varying between 0.5 and $2.0 \mathrm{~ms}$, is synchronized with the second laser pulse. Neither Mie scattering nor laser reflection is observed on $\mathrm{OH}^{*}$ images.

Several post-processing are performed on instantaneous $\mathrm{OH}^{*}$ images to obtain quantitative features of the flame dynamics. A Wiener filter applied on raw images allows limiting the high frequency noise while conserving high gradients of the reaction zones. Flame contour is obtained by image binarizationwith a threshold value chosen on the grey level histogram as the minimum between the background and the flame signals. Inside the contours, the mean flame location at each distance to the fuel bed is determined from the barycentre of $\mathrm{OH}^{*}$ chemiluminescence. The time resolved evolutions of the barycentre positions show linear progression from which a global flame speed can be deduced. As $\mathrm{OH}^{*}$ 
chemiluminescence is a marker of flame heat release, the evolution of relative flame intensity is obtained from each series of acquisitions. The flame topology is also obtained from $\mathrm{OH}^{*}$ images analysis. For each instantaneous image, two specific points are localised: the mean flame base along the line at $\mathrm{y}=2 \mathrm{~mm}$ from the fuel bed, and the upper flame tip as the highest location of the main flame contour. The distance of the latter to the fuel bed along the vertical axis of the CCD chip, i.e. perpendicular to the bed, is considered as the flame height. The flame length is defined as the distance between the two specific points, whereas the flame depth is the difference between their abscissa. Finally, the flame angle is calculated as the angle between the flame length line and fuel bed surface.

\section{Results}

\subsection{Flame front properties}

Examples of lateral views extracted from time series experiments performed during horizontal and upslope fire spread (fire tests $\mathrm{n}^{\circ} 2$ and 8, respectively) are displayed in Figure 2 for the whole set of cameras. The 3 cameras have different optical characteristics (focal length, sensor size and format) resulting in different field of view, a dotted square representing the common measurement area of the three systems was superimposed on the images. The video camera allows a global observation of the fire spreadingacross the fuel bed (Fig 2.a). During the experiments, the background is hidden with a black curtain located behind the combustion table, in order to obtain clean recording of the flames. Such occultation of the background is easy in the laboratory but cannot always be realizedat larger scale duringfield experimentsin the open. The PIV camera allows the visualization, in the light sheet, of the tracer particles entrained within the fluid flow (Fig 2.b) but the location of the flame front is missing in these images. Finally, the chemiluminescencecamera allowsrecording the location of the emission $\mathrm{OH}^{*}$ radicals during combustion processes in the flame (Fig 2.c). The advantage of such camera is that only the combustion regionsappear and the entire background is intrinsically filtered out. It should be noticed that the fields of view of all the cameras used in the present study are different due to the characteristics of each CCD sensor and attached lens. Nevertheless, post-processing allow overlaying the images from all cameras thanks to a calibration procedure, based on the image acquisition of a grid pattern set at the location of the laser sheet on the combustion table, and the localization of 4 reference points on these images. This enables to obtain the magnitude ratio, $\mathrm{M}$, for each camera setup and a same reference origin in the laboratory Cartesian coordinate system. For $\mathrm{OH}^{*}$ chemiluminescence imaging, the magnitude ratio is $\mathrm{M}_{\mathrm{OH}}\left(0^{\circ}\right)=1.92 \mathrm{~mm} /$ pixel for fire spread experiments across horizontal surface and $\mathrm{M}_{\mathrm{OH}}\left(30^{\circ}\right)=1.63 \mathrm{~mm} /$ pixel for $30^{\circ}$ up-slope tests. These magnitude ratios for PIV images are $\operatorname{MPIV}\left(0^{\circ}\right)=0.337 \mathrm{~mm} /$ pixel and $\operatorname{M} \operatorname{PIV}\left(30^{\circ}\right)=0.329$ $\mathrm{mm} /$ pixel, respectively.Conversely to the ones recorded by the PIV camera, the images from chemiluminescence camera do not represent a cross section of the flow but the whole of $\mathrm{OH}^{*}$ signalintegrated along the camera line of sight. Then, recording of $\mathrm{OH}^{*}$ signal at a specific location does not guarantee the presence of the flame in the central vertical plane where PIV measurements are performed. However, in a previous preliminary study (Morandini et al. 2012), recordings of the fire spreading from an upper front perspective, exhibited lateral fire contours with quasi linear shape during the experiments. Thus, when detected on $\mathrm{OH}^{*}$ chemiluminescence images, the probability is large that the flame should be present in the PIV plane. On the other hand, absence of $\mathrm{OH}^{*}$ signal on the image ensures that the corresponding region on the velocity field consists of fresh gases in front of the spreading fire or burnt gases in the plume.

Figures 3 and 4 present instantaneous $\mathrm{OH}^{*}$ chemiluminescence images extracted from temporal series of acquisitions respectively for non-slope and $30^{\circ}$ slopes configurations. These 
imagesshow the existence of two different fire behaviors and properties depending on slope angle. Flame fronts spreading across horizontal surface are nearly vertical while flames spreading upslope are tilted towards the unburned fuel. As a result, fire travelled faster across sloping beds and the rate of spread increased by a factor of 2 . The average rates of fire spread are 8.8 and $16.7 \mathrm{~mm} . \mathrm{s}^{-1}$ for horizontal and upslope conditions, respectively. It should be noticed that fire front spreading upslope accelerated but reached nevertheless a steady state in the second half of the combustion table. The flame inclination also increased during the fire propagation. Conversely, the quasi steady state is reached very sooner for horizontal fires.Flame front properties when steady state is reached are detailed in Table 1 for the whole fire tests. The results reveal nevertheless a satisfying repeatability of the experiments. It should be noticed that the rate of spread measured on this small-scale bench are lower than the ones previously measured with the same fuel on a larger facility (Dupuy and Maréchal2011; Dupuyet al. 2011; Silvaniet al.2012) due to scale effects. Indeed, the fire front width, which plays a significant role in the magnitude of the heat transfers at the centerline,is lesser in the present study.More particularly, under up-slope conditions, the fire perimeter could not develop a $\mathrm{V}$-shape. The fluctuations of the flame properties (rate of spread, flame length, angle, etc.) are higher when fire propagates upslope due to the more turbulent nature of the flame under these conditions. These properties are measured from chemiluminescence images but close results arealso obtained employing the image processing method to the video sequences. This underlines that flame property measurements can be also achieved at least cost, operating video camera provided that the background should be successfully occulted during fire tests. But the chemiluminescence camera provides also some information onfire intensity. Indeed, the measuredradiation results from the spontaneous emissions of shortlivedintermediate excited speciesOH* during combustion reactions and is strongly correlated with the rate of heat released(Ballesterand Garcia-Armingol 2010).

\subsection{Velocity fields and flame structures}

In PIV image processing, a cross-correlation between two images with known temporal separation is performed in each interrogation window that produces a signal peak corresponding to the most probable particles displacements in this area. Considering the magnitude ratios, the size of the interrogation window in which the velocity (displacement) is estimated, is $16.85 \times 16.85 \mathrm{~mm}^{2}$ and $16.45 \times 16.45 \mathrm{~mm}^{2}$ for horizontal and $30^{\circ}$ upslope experiments, respectively. Using interpolation schemes (two-dimensional Gaussian function) the PIV algorithm is able to achieve a sub-pixel accuracy of 0.1 pixel in the peak location. The uncertainties in the velocity estimation are thus $0.022 \mathrm{~m} / \mathrm{s}$ and $0.027 \mathrm{~m} / \mathrm{s}$ for horizontal and $30^{\circ}$ upslope experiments, respectively. With the PIV system used in this study, the velocity measurements present a dynamic range close to 200. This allows velocity measurements in the range of $0.03-6.00 \mathrm{~m} / \mathrm{s}$.

The instantaneous 2D velocity fields at the centerline of the bed of fuel are displayed with the corresponding chemiluminescence images on Figures 3 and 4 for both slope configurations (Fire Tests 4 and 7). Only 1 vector over 3 in both directions is represented on the velocity fields for sake of readability. The velocity vectors could be acquired in most of the measurement area thanks to a good seeding method and soot which seed the flame region. These data provide some important features for the understanding of flame spread mechanisms and therefore are of great interest for the validation of physical models of fire spread based on computational fluid dynamics. For both slope configurations, the zone of largest velocities corresponds to the plume region located above the intermittent flame. The peak values of instantaneous velocities in the core of the plume for horizontal and $30^{\circ}$ upslope fires are in the range of $1.3-2.2 \mathrm{~m}_{\mathrm{s}} \mathrm{s}^{-1}$ and $1.4-4.1 \mathrm{~m} . \mathrm{s}^{-1}$, respectively.Because of the turbulent 
nature of the flow, the fire plume shows strong velocity fluctuations. It should be noticed that the spatial resolution of the PIVcamera $(6.9 \mathrm{~mm}$ between 2 computed vectors) intrinsically cut-off the smallest vortices. Some hot gas structures from the burning zone periodically rise into the fire plume due to flame pulsation. The fire puffing frequency could not be determined accurately because of the characteristic time scale of the PIV measurements $(0.1 \mathrm{~s})$. Time resolved PIV with higher acquisition rate should be used for this purpose. Nevertheless, the results exhibit increasing velocity gradients with increasing the slope angle. Furthermore,instantaneous velocity fieldsshow vortical structures appearing at the upslope side of the fire plume (Fig. 5).

A closer view of thetime-averaged velocity vectors and $\mathrm{OH}^{*}$ contours in the neighborhood of the flame is displayed in Figures5 and 6. The flow streamlines, overlaid on these figures, help to assess the overall aerodynamic effects induced by the fire. These timeaveraged fields are based on five successive instantaneous ones, considering the short distance travelled by the fire within this period $(0.5 \mathrm{~s})$. Flame fronts spreading under no slope condition exhibit nearly vertical plume resulting in the great buoyancy forces generated by the fire. Inside the plume, the combustion gases are submitted to an upward buoyant acceleration. The magnitude of average velocity vector in this area is in the range of $1.2-2.0 \mathrm{~s}^{-1}$. Vertical profiles of horizontal $(\mathrm{Vx})$ and vertical $(\mathrm{Vy})$ velocity components at distances of 0.1 and $0.2 \mathrm{~m}$ from the flame front are plotted in Figure 7.a. Profiles of velocity components along the horizontal direction, at height of 0.05 and $0.2 \mathrm{~m}$ above the fuel bed top, are plotted in Figure 8.a. The shape of the profile (at constant height) of the time-averaged vertical velocity is quasisymmetrical. At the center of the flame, the horizontal velocity component is nil and the vertical component reaches a maximum value. Beside the flame, the buoyancy effects induce an influx of ambient air that is entrained laterally into the fire, equitably from both sides, resulting in quasi-vertical flames. The horizontal velocity of this induced flow can reach \pm $0.5 \mathrm{~m} . \mathrm{s}^{-1}$.These measurements confirm Anderson et al.(2010) estimations of the surface wind speed (reversal flow in the range of $0.3-0.6 \mathrm{~m} . \mathrm{s}^{-1}$ ) for horizontal fire spread in still air using kiel-static probes.This entrainment of ambient air into the fire suggests that nopreheating of the unburned fuel by convection can occurfar from the flame front.In this case, radiation is invoked as being the dominant heat transfer mechanism responsible of horizontal fire spread (Silvaniet al.2012). Indeed, under similar conditions, Lozano et al.(2010) found,from vorticity calculations, that convective heating assists preheating at a very short distance downwind of the flame front. However, the identification of the region ahead of the flame is difficult to obtain precisely from only PIV images. The authors only estimated the center of the fire, from the location of maximum vertical and minimum horizontalvelocities, but the flame interface could not be clearly identified. In the present study, the simultaneous acquisitions of $\mathrm{OH}^{*}$ chemiluminescence images with PIV measurements is one way to reach these information.

For fire spread under upslope conditions, the PIV measurements exhibit that the induced flow is strongly influenced by the slope. Air entrainment into the fire plume from the upslope side is restricted by the inclined bench. In this slope configuration, entrainment from both sides is not balanced anymore and the flames are tilted forward. Air entrainment at the burnt side of the fire exhibits a significant increase in comparison to the horizontal spread. The peak entrainment velocity in this region can reach $0.9 \mathrm{~m} . \mathrm{s}^{-1}$. It should be noticed that upslope flames exhibit different properties and behaviors during the propagation (Fig.7). Indeed, a transition between two regimes of fire spread is observedwhen fire travels into the second half of the fuel bed. This transitionis related to the fire acceleration previously observed on the rate of spread. The flame leans further forward as it spreads across the sloping bed of fuel and reaches a steady statein the middle of the bench $(x>45 \mathrm{~cm})$. The average flame height and velocity vector angle inside the flame (with respect to the support) areinitially $0.36 \mathrm{~m}$ and $45^{\circ}$ (Fig.6.a), respectively. Then, these values decreasesto $0.28 \mathrm{~m}$ and $28^{\circ}$, respectively (Fig.6.b). 
The airflow on the slope ahead of the flame is a key feature to understand fire spread mechanisms and associated heat transfers. Profiles of velocity components (parallel (Vx) and normal (Vy) to the bed surface) along the normal direction, at distances of 0.1 and $0.3 \mathrm{~m}$ from the flame front, are plotted in Figure 7.b-c.Profiles of velocity components along the horizontal direction, at height of 0.05 and $0.2 \mathrm{~m}$ above the fuel bed top, are plotted in Figure $8 . b-c$. In the region beneath the flame, the velocity vectorsclose to the bed surface $(5 \mathrm{~cm})$ show first the existence of an opposed flow (negative velocities with respect to fire spread direction) induced by the entrained air. The velocity magnitude of this incoming airflow is in the order of $0.3 \mathrm{~m} . \mathrm{s}^{-1}$ (Figs 7.b-8.b).Later during the spread, the velocity vectors in this region show the presence of a local wind, that blows upslope in the range of $0.5-1.7 \mathrm{~m} . \mathrm{s}^{-1}$ (Figs.7.c8.c), which pushes the hot gaseous products of combustion in contact with the unburned fuel. These results corroborate the findings of Dold(2009), from the observations of the displacement of soap bubbles, on the flow generated by the fire.These data thereforeconfirm the presence of significant convective heating (up to a distance of $0.15 \mathrm{~m}$ from the flame base), put to the fore in a previous study by heat flux measurements(Silvaniet al. 2012), which contributes to fire spread under slope conditions. The associated regime of fire spread then changes.In matters of fire suppression, highly dangerous operation conditions arise when the fire induces a flow of hot gases ahead of it that blows away from the fire rather than towards it. This flow attachment to the slope can explain the mechanism by which an unusually rapid fire spread can be generated in natural vegetation.

\section{Conclusions and perspectives}

A contribution to the understanding of the fluid dynamics of a fire spreading upslope across a bed of excelsior is provided in the present paper using coupled optical diagnostics. Despite its limited scale, this series of laboratory experiments contributes to the understanding of the fundamental physics of fire propagation across sloping beds.Mechanisms governing upslope fire spread dependsnot only on the increased radiant heat transferrate but also on convection induced by the aerodynamic effects, createdby the interaction between the fire induced flow and the slope. The coupling of PIV measurements and $\mathrm{OH}^{*}$ chemiluminescence imaging exhibits a substantial increase of fresh air entrainment at the burnt side of the fire during upward flame spread and an inversion of the direction of the local wind ahead of the flame front.

The present work constitutes a contribution to thestudy of the aerodynamics of upslope fires. The interaction between the slope and fire requires alsomore thoroughly investigations at a larger scale becausefire front and associated flow developthree dimensional features (Vshape) for wider fuel beds. Previous studies have indeed shown the development of fire whirls along the flank of $30^{\circ}$ upslope fires across large scale facility (Dupuy and Maréchal2011; Dupuyet al. 2011;Silvaniet al.2012), which mechanisms deserve further attention.

Under $30^{\circ}$ up-slope conditions, convection ahead of the fire front has been qualitatively identified but its quantitative measurement requires the estimation of both air velocity and temperature. Subsequent studies will also benefit the sampling at higher rates (time resolved PIV) to capture the evolution of the fluid dynamic structures in the fire plume and moreover the velocity fluctuations. Such measurements would also improve CFD modeling approaches where velocity and transported variables of the gas flow model are decomposedasasumofaverage and fluctuation contributions.Indeed, due to the scale dependence of the fire properties, Reynolds Average Navier-Stokes (RANS) or Large-Eddy Simulations (LES) approaches of turbulent combustion including radiation modeling are acknowledge as the most relevant tools for simulating large scale fires. Coupled optical diagnostics for combustion must be developedto provide the key quantities of the turbulent transport, namely the subgrid-scale Reynolds stress tensor and scalar fluxes. 
Acknowledgements: the authors are grateful to Alexis Coppalle, Martine Talbaut and Jérôme Yon who allowed to conduct the fire tests in their laboratory, at the COmplexe de RechercheInterprofessionnel en Aérothermochimie (CORIA UMR CNRS 6614).

\section{References}

Anderson WR, Catchpole EA, Butler BW (2010) International Journal of Wildland Fire 19:284-298.

Ballester JT (2010) Diagnostics techniques for the monitoring and control of practical flames. Prog Energy Combust Sci. 36:375-411.

Clark TL, Radke L, Coen J, Middleton D (1999) J. Appl. Meteorol., 38:1401-1420.

Dold JW, Zinoviev A (2009) Combustion Theory and Modelling 13:763-793.

DupuyJL (1995) International Journal of Wildland Fire 5 (3):153-164.

DupuyJL,Maréchal J (2011) International Journal of Wildland Fire 20:289-307.

DupuyJL,Maréchal J, Portier D, Valette JC (2011) International Journal of Wildland Fire 20:272-288.

DupuyJL,Morvan D (2005) International Journal of Wildland Fire 14:141-151.

Honoré D (2007) Advanced measurements in industrial combustion systems, in: Turbulent Combustion, L. Vervisch; D. Veynante; J. P. Van Beeck, (Eds.).

Honoré D, Maurel S, Quinqueneau A (2001) Particle Image Velocimetry in a semi-industrial $1 \mathrm{MW}$ boiler. The 4th International Workshop on PIV, Göttingen (Germany), Sept. 17-19.

Linn R, Winterkamp J, Edminster C, Colman JJ, Smith WS (2007) International Journal of Wildland Fire 16:183-195.

Lozano J,Tachajapong W, Weise DR, Mahalingam S, Princevac M (2010) Combustion Science and Technology 182:858-878.

Mendes-Lopes JMC, Ventura JMP, Amaral JMP (2003) International Journal of Wildland Fire 12:67-84.

Morandini F, Silvani X, Honoré D,Boutin G, Susset A, Vernet R (2012) Diagnostics non intrusifs couplés des champs dynamiques et scalaires de flammes d'incendie naturel en propagation, 3e Congrès Francophone de Techniques Laser, CFTL 2012, Rouen, 18-21 Septembre 2012, p. 27.

Morandini F,Silvani X,Susset A (2012) Experiments in Fluids 53:237-244.

Silvani X, Morandini F,Dupuy JL (2012) Experimental Thermal and Fluid Science 41:99-111. Susset A, Most J and Honoré D (2006) Experiments in Fluids 40:70-79.

Viegas DX (2006) International Journal of Wildland Fire 15:169-177.

Zhou X, Mahalingam S, Weise D (2007) Proceedings of the Combustion Institute 31:25472555. 